\title{
Inefficient Intra-Firm Incentives Can Stabilize Cartels in Cournot Oligopolies.
}

\author{
Roland Kirstein* Annette Kirstein** \\ January 2006 / draft 09
}

\begin{abstract}
The paper demonstrates that the inherent instability of Cournot cartels can be overcome by collective wage agreements if these agreements are legally enforceable. The parties have to agree upon linear contracts with minimum variable and fixed wages.

Beyond its relevance for strategic management, this insight has an implication for economic policy: competition authorities should observe collective wage agreements for their potential collusive effect on product markets. Moreover, the model offers a new explanation for the "fixed wage puzzle", i.e., the observation that firms pay lower than efficient variable wages and higher fixed wages than predicted by contract theory.
\end{abstract}

JEL classification: C72, C78, D43, J33, J50, K31, L41

Encyclopedia of Law and Economics: 5550, 5300, 0550

Keywords: Principal-agent theory, piece rate, fixed wage, collective wage agreements, Nash bargaining solution.

\footnotetext{
${ }^{*}$ Corresponding author. Center for the Study of Law and Economics (CSLE), University of Saarland, D-66041 Saarbrücken, Germany (email: rol@mx.uni-saarland.de). We are grateful to Max Albert, Siegfried Berninghaus, Myriam Doriat-Dobain, Hans Gerhard, Jean-Daniel Guigon, Peter Jost, Martin Kolmar, Veronika Nolte, Clemens Puppe, Roseanna Ravsin, Dieter Schmidtchen, Viktor Vanberg, Birgit Will and other seminar participants in Bonn, Freiburg, Karlsruhe, Mainz, Nancy, Saarbrücken and Vallendar for helpful comments. Remaining errors, however, remain our responsibility.

** Sonderforschungsbereich 504 "Bounded Rationality", University Mannheim, and Institut für Wirtschaftstheorie and Operations Research, University of Karlsruhe, D-76128 Karlsruhe, Germany, (email: Kirstein@wiwi.uni-karlsruhe.de).
} 


\section{Introduction}

This paper analyzes how cartels can be stabilized by collective wage agreements that introduce inefficient intra-firm incentives. Cartel agreements in Cournot oligopolies suffer from an inherent instability: no cartel solution is a Nash equilibrium, because each competitor has an incentive to choose an output greater than his cartel quota. Moreover, cartel agreements are in general not legally enforceable. ${ }^{1}$

The above analysis rests on the assumption that production takes place in the absence of intra-firm conflicts. In our paper, we acknowledge that intra-firm conflicts which result from delegation and moral hazard problems may exist in oligopolistic firms. These conflicts are modeled as principal-agent problems. The principal is unable to choose the firm's output directly, but can influence it by choosing appropriate variable payments ("piece rates") and fixed wages. Thus, the firm owners face two problems: the instability of a cartel, and the intra-firm conflict with their respective agents. We demonstrate that these two problems do not reinforce each other. To the contrary, the principals can stabilize their cartel by a collective wage agreement that provides inefficient intra-firm incentives. ${ }^{2}$

In a world with risk neutral agents and risk neutral principals, efficient intrafirm incentives can normally be achieved when the agent is assigned the position of the residual claimant. If the principal has complete bargaining power, he may capture the complete cooperation rent via the fixed wage. A contract that provides a piece rate smaller than the efficient one for the risk neutral agent implements lower than efficient effort. The firm's output is, c.p., smaller than under a first-best contract. ${ }^{3}$

We consider a two-stage interaction: during the first stage, the Cournot competitors close an agreement about intra-firm incentives. In the second stage, outputs are produced and sold. We show that firms can, during the first stage, calibrate the intra-firm incentives inefficiently and thereby establish the cartel solution as a Nash equilibrium in the second stage. However, such an agreement is not a subgame perfect equilibrium in the two stage game. Each firm had an incentive to deviate by offering efficient intra-firm incentives to its own agents, even if all other firms did obey the agreement. With respect to this instability

\footnotetext{
${ }^{1}$ The shadow of the future may induce cartel agreements as Nash equilibria. In this paper, we focus on one-shot games. In repeated games, however, the non-trivial problem of equilibrium selection arises because the cartel supergame has an infinite number of Pareto-efficient Nash equilibria.

${ }^{2}$ Collective wage agreements with profit-sharing elements are quite common. E.g., the "'Big Three" automobile producers have introduced profit sharing components into the workers' compensation after 1979, see Katz/MacDuffie/Pil $(2002,22)$. The US automobile industry traditionally has a pattern setting role for the collective wage bargaining in the US.

${ }^{3} \mathrm{~A}$ similar result would be achieved if a risk-averse agent is employed instead of a risk neutral one: only second-best solutions are attainable, because a trade-off between risk allocation and incentives cannot be circumvented. A third variation of intra-firm inefficiency would be an organization with many agents: if the compensation for these agents is characterized by a budget-balanced sharing rule, this induces inefficient intra-firm incentives, see Holmstrom (1982).
} 
problem, there is no difference between an indirect cartel agreement in wages and the direct cartel in output quotas.

Yet, there is a simple and legal way to solve the instability problem of the indirect cartel agreement. All Cournot competitors may agree upon an industrywide collective wage agreement with a labor union, based on linear contracts, in order to establish minimum wages and thereby introduce inefficient intra-firm incentives. The important difference between a direct cartel agreement and a collective wage agreement is that the latter can be legally enforced.

If the firms have full bargaining power and can make a take-it or leave-it offer, then the indirect cartel agreement enables them to divide the full monopoly profit among them. Even if the Union demands a share of the cartel profit for its members, the Nash bargaining solution would guarantee each competitor a share that is at least as large as its profit under the Cournot solution.

Section 2 presents the related literature. Many papers on managerial incentives may not exactly capture the real-world meaning of the term "manager". In a large corporation, a manager is usually an employee on the higher levels of a hierarchy whose tasks consist of supervising and planning rather than directly producing the firm's output. The typical principal-agent model, however, sees the manager as the provider of "effort", a crucial (and often the only) input which is required to produce the firm's output. We follow the terminology of the economic literature here without claiming that the derived results could be applied to, e.g., a CEO.

The domain of our study is, therefore, limited to input providers with linear contracts, i.e., who receive a variable and a fixed wage, which can be made subject of an enforceable collective wage agreement. ${ }^{4}$ Moreover, labor is the only input and wages are the only costs the firms have to bear. ${ }^{5}$ A "piece rate" in this context is simply a share of the value of the respective firm's output. A fixed wage may also take the form of health care or pension benefits.

The model we set up in section 3 acknowledges the presence of intra-firm conflicts within each firm. These conflicts have to be solved by incentive contracts. Therefore, we re-model the Cournot duopoly as a game in wages rather than in outputs in section 3.1. We derive the agents' reactions to contract offers, the duopolists' reaction curves in piece rates, and the decentralized Cournot solution in section 3.2. In section 3.3, we demonstrate the monopolistic cartel agreement in wages, and its instability. Furthermore, we prove that an enforceable collective agreement on minimum wages may stabilize the cartel solution. Finally, we demonstrate the symmetric Nash bargaining solution between labor union and employers association (in section 3.4). In section 4, we draw conclusions.

\footnotetext{
${ }^{4}$ Alexander/Reifen (1995) show that collusive minimum-price two-part tariff agreements require an outside enforcer, while price ceilings are self-enforcing.

${ }^{5}$ Tombak (2002) looks at mergers between firms with different costs.
} 


\section{Related literature}

Papers on the principal-agent problem, as well as on oligopoly theory, are too numerous to count. Surprisingly, the number of papers that simultaneously model Cournot competition between firms and the existence of intra-firm conflicts between owners and managers is rather small. The most prominent idea in this field is that product market competition may serve as a device to discipline managers, and thereby contribute to the solution of the latter. ${ }^{6}$ Hart (1983) has rigorously derived conditions under which increased product market competition can reduce "organizational slack". The driving force in his model is the information about his agent a principal can gain from observing the competitors. ${ }^{7}$ Hermalin (1992) has shown that competition can provide incentives for managers to work harder even if inference from market outcomes is excluded. Schmidt (1997) leaves aside the information function of product market competition and rather focuses on its effect on the firms' profits. He finds that decreasing profits may have ambiguous effects on the manager: on the one hand, they induce higher effort, as the bankruptcy risk is increased. On the other hand, the firm's scope for paying rents to the manager (and thereby foster his incentives) becomes smaller.

The empirical evidence on the relationship between managerial incentives, competition and firm's performance is mixed. Nygaard/Myrveit (2000) have examined several types of contractual relations in Norway. Gaver/Gaver/Battistel (1992) have not found significant stock market reactions to the introduction of performance payment schemes for top managers. Nickell (1996) acknowledges that there are some theoretical reasons for the idea that product market competition improves corporate performance, but they are "not overwhelming", and the empirical evidence is weak. The mutual impact of competition and intrateam incentives is the subject of the experimental paper by Bornstein/Gneezy (2002). However, the intra-firm conflict in their paper is represented by two types of coordination games to be played between the team members (either a "chicken" game or a "coordination" game), while the teams compete in a Bertrand market. The intra-firm incentives are exogenously given and constitute the type of the firm. In our model, both market behavior and choice of intra-firm contracts are endogenous.

Another branch of the existing literature in this field is concerned with the macroeconomic effects of imperfect product market competition, see Amable/ Gatti (2002), and with its impact on manager employment. ${ }^{8}$ Profit-sharing may influence employment, as it has been analyzed by Weitzman (1985), Stewart (1989) and Hart (1990).

Some other papers deal with isolated aspects of the interplay between intrafirm incentives and competition: Glazer/Israel (1990) have shown that management compensation schemes can serve as a signaling mechanism on the prod-

\footnotetext{
${ }^{6}$ See Berle/Means (1932) and Leibenstein (1966).

${ }^{7}$ This is also the core idea in Nalebuff/Stiglitz (1983). In Gal-Or (1995), it is the payment schedule that has an informational (and a strategic) component in equilibrium.

${ }^{8}$ See Amable/Gatti (2001), Fee/Hadlock (2000), and Kühn (1994).
} 
uct market. Toulemonde (1999) has observed that the wage structure may deter potential competitors from market entry. Richards (1983) points out that wage-spillovers should be taken into account when analyzing a market which is characterized by a dominant firm and some smaller competitors. Goering/Harikumar (1999) describe how managers' incentives to invest in longand short-run projects are afflicted by competition. Aggarwal/Samwick (1999) explain the lack of compensation schemes that are based upon relative performance by the strategic interaction between the firms. Gonzáles-Maestro (2000) the number of firms which makes divisionalization profitable; this number is greater in oligopoly markets than in other divizionalization models. Saracho (2002) explains the role of royalties in a a patent licensing model with strategic delegation and managerial incentives.

A paper which is close to ours is Sklivas (1987). ${ }^{9}$ The author asks whether firms in an oligopoly actually choose intra-firm incentives so as to maximize profits. The existence of intra-firm conflicts implements market outcomes that are more competitive than those in the Cournot model without intra-firm conflicts. This result is driven by the assumption that contracts cannot be made contingent on quantity outcomes. The agent's payment depends on a linear combination of the firm's profit and returns. The same assumption has been made by Fershtmann/JUDD (1987). It is the most striking result of these two papers that it optimal for principals to offers rewards which are contingent on a linear combination of profit and returns. The results differ substantially from ours, as we assume linear contracts. Moreover, both papers do not make explicit the incentive mechanism, and they neglect its impact on the firms' costs. In our paper, we explicitly model the incentive problem and include the agents' wages into the firms' cost functions. Finally, both papers overlook the collusive potential of a collective wage agreement, which is the subject of our model.

Another paper which appears to be close to ours at the first glance is Bensaïd/ Gary-Bobo (1991). In their model, however, effort costs within the firm are assumed to be zero. Therefore, profit-sharing contracts or fixed wages only serve to satisfy the participation constraint. Haucap/Pauly/Wey (2001) is also close to our subject, but their model highlights a different anti-competitive aspect of collective wage setting. They start with two types of firms in one industry, one type produces with a labor-intensive technology, the other operates capital-intensive. The latter type finds it beneficial to agree upon high wages in a collective wage agreement, which raises rivals' costs and increases the own market share. In our model, the firms are homogeneous, and it is the wage structure (piece rate vs. fixed wage) that plays the crucial role.

\footnotetext{
${ }^{9}$ Reitman (1993) has chosen the same approach to analyze the impact of stock-options as managerial compensation.
} 


\section{The model}

\subsection{Setup}

Consider a market with two firms, labeled 1 and 2 . We will refer to the firm owners as principals $P_{1}$ and $P_{2}$. The output of firm $i$ is generated by an agent $A_{i}$ who spends effort denoted $e_{i} ; i \in\{1 ; 2\}$. Providing the effort level $e_{i}$ causes $\operatorname{costs} c_{i}\left(e_{i}\right)=e_{i}^{2}$. No other firms or agents may enter the game. The production functions of firm $i$ is $Y_{i}\left(e_{i}\right)=e_{i}+\eta_{i}$ where $Y_{i}$ measures the amount of output. $\eta_{i}$ is a random variable with positive variance and zero expected value. The realizations of the random variables and the actual efforts by the Agents are unobservable and unverifiable (and it is impossible to infer the actual effort from the observed output). Hence, a compensation scheme cannot be made contingent on input. We limit our view to fixed wages and piece rates. If a contract offer is rejected, then the respective agent receives his outside option $u \geq 0 . .^{10}$

All four players are assumed to be risk-neutral (and limited liability problems are neglected). Thus, each random variable can be replaced by its expected value when deriving the players behavior. The expected output of firm $i$ can, therefore, be simplified to $Y_{i}=e_{i}$. The total (expected) amount produced in the market is $Y=e_{1}+e_{2}$. The consumers' inverse demand is $p=a-Y$ with $a>0$, where $p$ represents the price charged by the firms. The two firms have, in principle, three ways to interact with each other:

- they can choose their strategies without coordination. We analyze this duopoly game in section 3.2 .

- They can try to coordinate their behavior without making use of an institutional framework to stabilize this coordination. The resulting cartel game is analyzed in section 3.3. We first derive the piece rate a cartel would set in order to maximize its joint profit, and we compute the additional profit generated by the cartel solution. Our analysis shows that this cartel solution is not an equilibrium, but can be stabilized by an enforceable minimum wage agreement.

- Finally, the firms can negotiate with a labor union about a collective minimum wage agreement in the first place. We analyze the third game in section 3.4. Without such an agreement, the players enter the duopoly game which is, hence, a subgame of the third game and constitutes the threat points of the bargaining parties. With an agreement, the parties enjoy the benefits of the cartel solution derived in the second game. However, as the negotiations about the collective wage agreement involve the labor union, the cartel has to share the additional profit with its employees when applying the Nash bargaining solution to the first stage of the game.

\footnotetext{
${ }^{10}$ For technical reasons we assume $u<a^{2} / 5$, only to guarantee that duopolists may find it interesting at all to engage in this market.
} 
We assume collective wage agreements to be perfectly enforceable: it is, therefore, impossible to deviate downwards if such an agreement prevails (the collective wage agreement imposes minimum wages). However, each employer is free to offer a higher compensation parameter to his agent.

\subsection{Duopoly wages}

In this section, we analyze uncoordinated behavior between the two firms. The interaction takes place in three stages.

- The two principals $P_{i}, i \in\{1 ; 2\}$ offer contracts $\left(F_{i}^{D}, w_{i}^{D}\right)$ to their respective agent $A_{i}$. The index $D$ indicates the duopoly situation.

- Each agent $A_{i}$ decides whether to accept the contract offer of his principal. If he rejects it, he receives his outside option $u$ and the respective principal produces nothing.

- If, on the other hand, agent $A_{i}$ accepts the contract offer by his principal $P_{i}$, he chooses his effort $e_{i}$. The output $Y_{i}\left(e_{i}\right)$ is produced, the market price for the good is determined, the total output is sold, and payoffs are paid.

The Cournot solution in wages is derived by backwards induction. First, we determine the optimal reaction of the respective agent to his principal's contract offer. The effort choice of the respective agent determines the firm's output. Then we analyze the wage setting game between the two firms (each of them anticipating its agent's reaction).

\subsubsection{The agents' choices}

In the last stage, each of the agents $A_{i}$ faces the following maximization problem: $e_{i}^{*}=\arg \max F_{i}+w_{i} Y_{i}\left(e_{i}\right)-c_{i}\left(e_{i}\right)$. With $Y_{i}=e_{i}$ and $c_{i}=e_{i}^{2}$, the first-order condition for an internal maximum is $w_{i}=2 e_{i}$. Hence, the optimal effort reaction of each agent to a wage offer by his respective principal $w_{i}$ is

$$
e_{i}^{*}\left(w_{i}\right)=\frac{w_{i}}{2} .
$$

In the third stage, each agent decides whether to accept the respective contract. Anticipating his own later effort reaction, agent $i$ expects, when accepting the contract, a payoff that amounts to $F_{i}+w_{i} Y_{i}\left[e_{i}^{*}\left(w_{i}\right)\right]-c_{i}\left[e_{i}^{*}\left(w_{i}\right)\right]$. Using the production function and effort cost, this equals $F_{i}+w_{i}^{2} / 4$. Agent $A_{i}$ accepts if this payoff is at least as high as his outside option $u$. Therefore,

$$
F_{i}\left(w_{i}\right)=u-w_{i}^{2} / 4
$$

is the minimum fixed wage that obeys the participation constraint of agent $A_{i}$. 


\subsubsection{Contract offers in the duopoly}

Using equations (1) and (2), the choice problem of each principal in stage 2 of our game can be reduced to one in piece rates $w_{i}$ and $w_{j}$. In the subgame without a collective wage agreement, both principals do not have to obey legal constraints when choosing their piece rate offer. They anticipate that at least a fixed wage of $F_{i}=u-\left(w_{i}^{2} / 4\right)$ is required to make an offer $w_{i}$ acceptable for their respective agent. Moreover, they anticipate that this offer will implement $e_{i}=w_{i} / 2$ as their agent's effort choice. Thus, the profit function of principal $i$ in the Cournot duopoly subgame is $\Pi_{i}^{D}\left(w_{i}, w_{j}\right)=\left[p\left(e_{i}\left(w_{i}\right)+e_{j}\left(w_{j}\right)\right)-w_{i}\right] e_{i}\left(w_{i}\right)-F_{i}$ with $i, j \in\{1 ; 2\}$ and $i \neq j$. This yield function can, by making use of the results derived above, be rewritten as

$$
\Pi_{i}^{D}\left(w_{i}, w_{j}\right)=\left[a-\frac{w_{i}+w_{j}}{2}-w_{i}\right] \frac{w_{i}}{2}-\left(u-\frac{w_{i}^{2}}{4}\right) .
$$

Each firm chooses its piece rate in order to maximize its profit. The first-order condition for firm $i$, given an internal solution exists, is $a / 2-w_{i}-w_{j} / 4=0$. Hence, the optimal reaction of firm $i$ to the other firm's choice $w_{j}$ is

$$
w_{i}^{D}\left(w_{j}\right)=\frac{2 a-w_{j}}{4} .
$$

Substituting $w_{j}\left(w_{i}\right)$ into equation (3) yields the Cournot duopoly solution $w_{i}^{D}=$ $w_{j}^{D}=2 a / 5$. The corresponding minimum fixed wages are $F_{i}^{D}=u-a^{2} / 25$.

By offering $\left(F_{i}^{D}, w_{i}^{D}\right)$, both firms implement an individual output of $e_{i}^{D}=$ $a / 5$. The market output, thus, amounts to $Y^{D}=2 a / 5$, and the market price is $p^{D}=3 a / 5$. Each firm's profit then accrues to $\Pi_{i}^{D}=2 a^{2} / 25-u$. The agents receive their outside option $u$.

In equilibrium, the return of firm $i$ is computed as $R_{i}^{D}=\left(a-e_{i}^{D}-e_{j}^{D}\right) e_{i}^{D}$. The marginal return then is $M R_{i}^{D}=a-e_{j}^{D}-2 e_{i}^{D}$. Anticipating both agents' reactions, the marginal return can also be expressed in wages, namely $M R_{i}^{D}=$ $a-w_{i}-w_{j} / 2$. Substitution of the equilibrium piece rates yields $M R_{i}^{D}=$ $2 a / 5$. In equilibrium, both firms therefore choose piece rates equal to their marginal returns. Thus, the piece rate is set efficiently, seen from the individual's perspective.

\subsection{Cartel wages and the instability problem}

In this section, we analyze the two firms' attempt to coordinate their behavior without first entering into the institutional framework of a legally enforceable collective wage agreement. We assume that the two firms may agree upon piece rates and fixed wages before making their individual offers to their agents. However, such an agreement is not binding (we introduce enforceable agreements in the next section).

The agents' effort choices are governed by the same reaction functions as derived above, see equation (1), which is anticipated by the cartel members. 
Hence, we can limit the analysis to the firms' choices. We proceed in three steps:

- first, we derive what piece rates a cartel would set in order to generate the maximum profit.

- Then we show that this cartel solution is not an equilibrium.

- Finally we demonstrate that an enforceable minimum wage agreement would stabilize the cartel solution.

\subsubsection{Optimal piece rates in the cartel}

In this section, we apply the maximization problem of a monopolist who produces in two production sites with increasing marginal costs to our problem. Such a monopolist has the following profit function:

$$
\Pi^{C}=\left[p\left(e_{i}\left(w_{i}\right)+e_{j}\left(w_{j}\right)\right)-w_{i}\right] e_{i}-F_{i}+\left[p\left(e_{i}\left(w_{i}\right)+e_{j}\left(w_{j}\right)\right)-w_{j}\right] e_{j}-F_{j} .
$$

The anticipated reactions of the two agents employed by the cartel are the same as derived above. Therefore, we can simplify the cartel's profit to

$$
\Pi^{C}=\frac{a\left(w_{i}+w_{j}\right)-w_{i}^{2}-w_{j}^{2}-w_{i} w_{j}}{2}-2 u .
$$

The first-order conditions for an internal solution are $\left(a-2 w_{i}-w_{j}\right) / 2=0$ and $\left(a-2 w_{j}-w_{i}\right) / 2=0$. A cartel planner has to choose $\left(w_{i}, w_{j}\right)$ such that these conditions are simultaneously fulfilled. Imagine the planner considers a certain value of $w_{j}$; his optimal "reaction" $w_{i}$ is described by

$$
w_{i}^{C}\left(w_{j}\right)=\frac{a-w_{j}}{2}
$$

The planner's equilibrium is characterized by the intersection of the planning curves $w_{i}^{C}\left(w_{j}\right)$ and $w_{j}^{C}\left(w_{i}\right)$. Compare the planning curve to the reaction curve of a Cournot duopolist (see equation 3 above) who picks his piece rate in a decentralized choice. It is obvious that both sets of curves (in a $w_{i}$ - $w_{j}$-diagram) have the same intercept, namely $a / 2$, but different slopes: the cartel planning curves are steeper than the Cournot reaction curves. The relation between these two sets of curves is depicted in figure 1 .

The profit maximizing piece rates for both production sites of the cartel is $w_{i}^{C}=w_{j}^{C}=a / 3$. The corresponding minimum fixed wage that induces the agents to accept their contract offer is, for both firms, $F_{i}^{C}=u-a^{2} / 36$. Hence, $F_{i}^{C}>F_{i}^{D}$.

A contract offer $\left(F_{i}^{C}, w_{i}^{C}\right)$ induces efforts $e_{i}^{C}=e_{j}^{C}=a / 6$. Thus, the cartel produces $Y^{C}=a / 3$ as its total output. The market price then is $p^{C}=2 a / 3$, and the individual profits of the two cartel members amount to $\Pi_{i}^{C}=a^{2} / 12-u$. In the unique cartel solution, each firm collects a higher profit than as a Cournot 
Figure 1: Cournot reaction and cartel planning

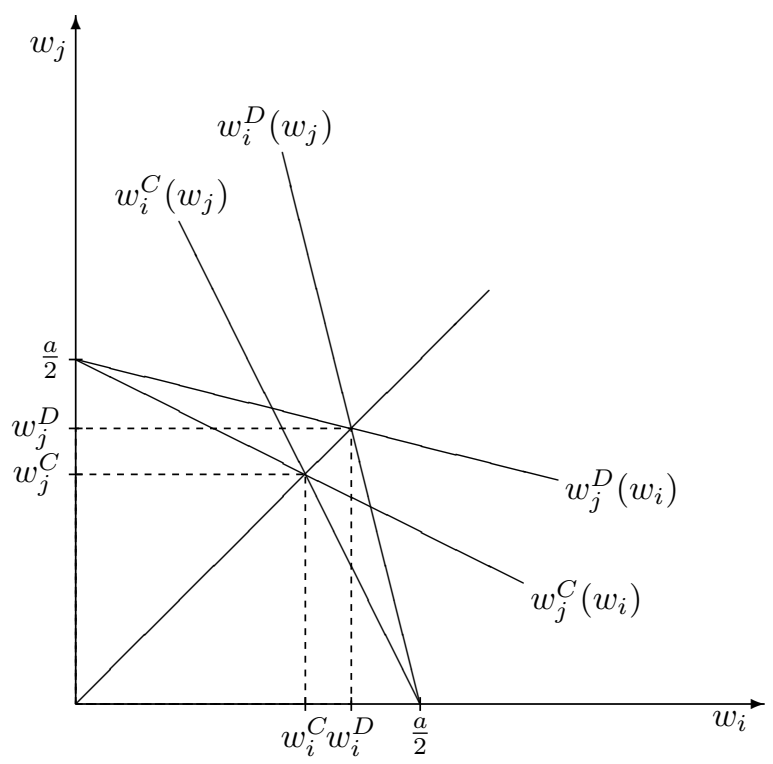

duopolist: $\Pi_{i}^{C}>\Pi_{i}^{D}$. In the cartel optimum, each firms' revenues are computed as

$$
M R_{i}^{C}=a-\frac{w_{j}^{C}}{2}-w_{i}^{C}=a / 2 .
$$

Obviously, the cartel solution is characterized by $M R_{i}^{C}>w_{i}^{C}$. The marginal revenue of each firm exceeds the piece rate offered to its agent. Individually efficient would be a piece rate equal to the marginal revenue. In this sense, the cartel would agree upon wages that create inefficient intra-firm incentives. Table 1 compares the results of the decentralized Cournot model and the centralized cartel planning.

\subsubsection{Incentives to deviate from a collective wage agreement}

We have demonstrated three results so far:

- the Cournot duopoly game in outputs can be restated as a game in wages if the firms face an intra-firm incentive problem. The piece rate determines the respective firm's (expected) output.

- In the duopoly situation, the firms under consideration would choose a piece rate $w_{i}^{D}=2 a / 5$, while the cartel would pay a smaller piece rate, namely $w=a / 3$, and thereby reduce the collective output.

- Even though the cartel members are required to pay a higher fixed wage 
Table 1: The main results of Cournot and cartel

\begin{tabular}{r|r|r|c} 
& Cournot duopoly & cartel & comparison \\
\hline$w_{i}$ & $2 a / 5$ & $a / 3$ & $w_{i}^{D}>w_{i}^{C}$ \\
$\operatorname{minimum} F_{i}$ & $u-a^{2} / 25$ & $u-a^{2} / 36$ & $F_{i}^{D}<F_{i}^{C}$ \\
$e_{i}$ & $a / 5$ & $a / 6$ & $e_{i}^{D}>e_{i}^{C}$ \\
$Y$ & $2 a / 5$ & $a / 3$ & $Y^{D}>Y^{C}$ \\
$p$ & $3 a / 5$ & $2 a / 3$ & $p^{D}<p^{C}$ \\
$\Pi_{i}$ & $2 a^{2} / 25-u$ & $a^{2} / 12-u$ & $\Pi_{i}^{D}<\Pi_{i}^{C}$ \\
$\Pi$ & $4 a^{2} / 25-2 u$ & $a^{2} / 6-2 u$ & $\Pi^{C}-\Pi^{D}=a^{2} / 150>0$ \\
$M R_{i}\left(e_{i}\right)$ & $2 a / 5$ & $a / 2$ & $M R_{i}^{D}=w_{i}^{D} ; M R_{i}^{C}>w_{i}^{C}$ \\
\hline
\end{tabular}

to their agents than in the Cournot oligopoly, cartelization would increase the group profit by $\Pi^{C}-\Pi^{D}=7 a^{2} / 225$.

The desirability of the cartel solution, however, does not imply that it is stable. As it is shown in figure 1, the optimal cartel choice does not lie on the Cournot reaction curves. Moreover, the cartel piece rate is smaller than each cartel member's marginal revenue. Hence, both cartel members have an incentive to deviate upwards from the cartel agreement in the second stage of the game.

Now we demonstrate that a collective agreement about minimum wages forms an effective obstacle against such deviation, even though it allows for upwards deviations. A cartel member who tries to offer a higher piece rate simultaneously wishes to pay a lower fixed wage which, however, is prohibited by the collective wage agreement. We demonstrate that no incentive exists to increase the piece rate without decreasing the fixed wage.

Figure 2 illustrates the intra-firm incentives. First of all, the figure shows the participation constraint of agent $A_{i}$. The participation constraint consists of $F_{i}-w_{i}$ combinations which leave the agent with an (expected) payoff equal to $u$. It is a falling curve with intercept $u$ at the $F_{i}$-axis. The agent prefers $F_{i}-w_{i}$-combinations above the participation constraint, as indicated by the tiny arrow.

Furthermore, figure 2 shows the cartel solution (point $\mathrm{C}$ ) and the duopoly solution (point D). In addition to this, the area to the north-east of $\mathrm{C}$ depicts the compensation parameter combinations the firms are allowed to offer under a collective minimum wage agreement (this area is called "permitted deviations from C").

The last component of figure 2 is the iso-profit curve of firm $P_{i}$ that represents its individual profit level in the cartel solution. Denote this profit level as $\Pi_{i}^{C}$. In general, a firm's iso-profit curve in a $F_{i}$ - $w_{i}$-diagram for the profit level $\Pi_{i}$ is given by

$$
F_{i}=\frac{2 a-w_{j}}{4} w_{i}-\frac{3}{4} w_{i}^{2}-\Pi_{i} .
$$


Figure 2: Intra-firm incentives

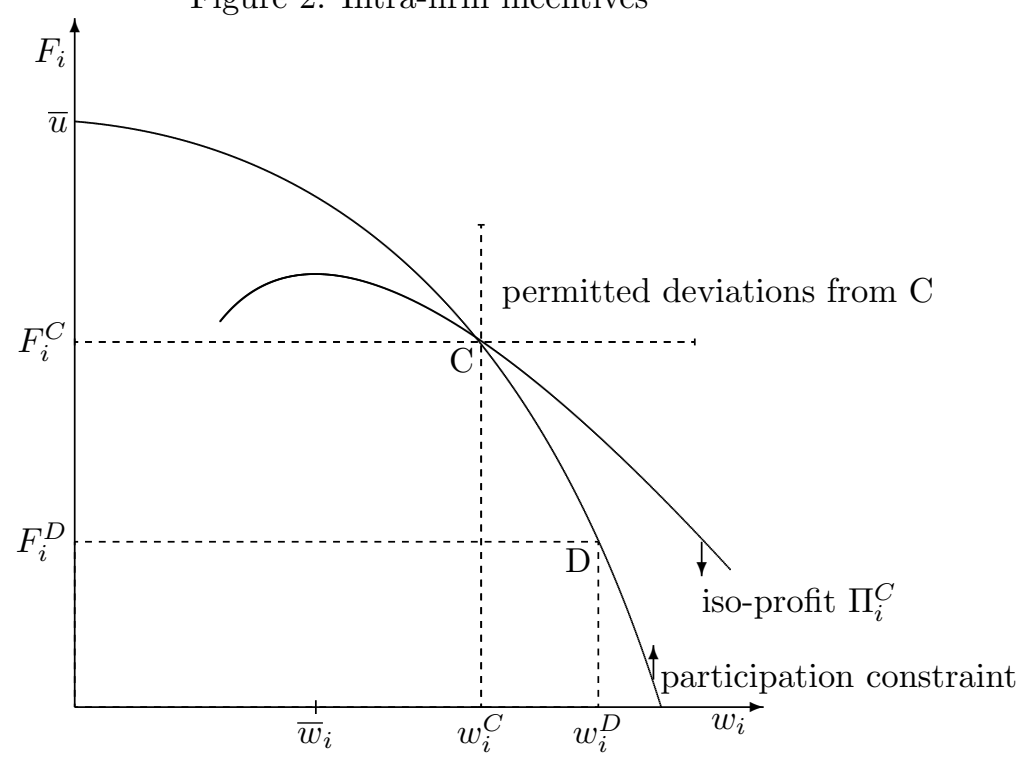

The cartel situation is characterized by $w_{j}=a / 3$ and $\Pi_{i}=\Pi_{i}^{C}$, and the isoprofit curve of $P_{i}$ can be simplified to

$$
F_{i}=\frac{5 a}{12} w_{i}-\frac{3}{4} w_{i}^{2}-\Pi_{i}^{C} .
$$

If the other firm sets the cartel wage $w_{j}=a / 3$, then all iso-profit curves of $P_{i}$ have their maximum at $\bar{w}_{i}=5 a / 18$. Note that $\bar{w}_{i}<w_{i}^{C}$. The first derivative of this iso-profit curve with respect to $w_{i}$ is

$$
\frac{\partial F_{i}}{\partial w_{i}}=\frac{5 a}{12}-\frac{3}{2} w_{i} .
$$

For $w_{i}>5 a / 18$, the iso-profit curve representing $\Pi_{i}^{C}$ has negative slope. This is surprising, as the marginal profit in the cartel solution is positive: the principal should be able to offer the agent a higher piece rate and still collect a higher piece rate. If this were true, then the iso-profit curve would have positive slope. But recall that the collective wage agreement is, in our model, limited to linear contracts. In this framework, a higher piece rate leads to higher costs also with regard to the infra-marginal units. Hence, an increase of the piece rate decreases the profit, which has to be compensated by a lower fixed wage. Thus, the iso-profit curve has negative slope. However, it is flatter than the agent's participation constraint. The principal prefers wage combinations below it, as the tiny arrow indicates. Hence, the iso-profit curve and the participation constraint open up an area which contains wage combinations that are bilaterally 
beneficial for the principal and his agent, compared to the collective wage agreement.

Even though the collective wage agreement maximizes their joint profit, both firms have an incentive to deviate unilaterally, as this generates a higher individual profit, however combined with a negative externality to the disadvantage of the other firm. E.g., choosing the piece rate $w_{i}^{D}$ instead of $w_{i}^{C}$ (and adjusting the fixed wage accordingly) would generate a higher profit for firm $i$, provided firm $j$ sticks to $w_{j}^{C} .{ }^{11}$ The profit effect can easily be seen in figure 2 , where point $\mathrm{D}$ is situated on a iso-profit curve of higher value than the point $\mathrm{C}$.

A unilateral deviation is only attractive if it consists of an increased piece rate and a lowered fixed wage - a move towards south-east in figure 2 . The collective minimum wage agreement, however, only allows the principals to deviate towards north-east. The only intersection between the lens and permitted deviations is the point $\mathrm{C}$ itself. The collective wage agreement, therefore, effectively implements a "fixed wage brake" against the temptation to deviate.

\subsection{The collective wage agreement}

In the previous sections we have demonstrated that a cartel agreement with $F_{i}^{C}$ and $w_{i}^{C}$ attains a monopoly solution and, thereby, maximizes the firms' value. Furthermore, it is stable if downwards deviations are effectively prohibited. Hence, it generates an agreement rent between the parties of the collective wage agreement. In this section, we derive the symmetric Nash-bargaining solution. ${ }^{12}$.

The game now consists of four stages:

1. The employers' association representing firms $P_{1}$ and $P_{2}$ bargains with the labor union (which represents workers $A_{1}$ and $A_{2}$ ) over a collective wage agreement. Such an agreement consists of a minimum fixed wage, denoted $F^{B}$, and a minimum piece rate $w^{B}$ (the index $B$ denotes that these contract parameters are the result of a bargaining process). This stage may end with or without an agreement.

2. The two principals separately offer "their" agent a contract $\left(F_{i}, w_{i}\right)$. If no agreement was concluded during the first stage, the players enter the Cournot duopoly game analyzed in section 3.2. The outcome of this game, therefore, constitutes the threat points of the bargaining parties. If, on the other hand, a collective wage agreement $\left(F^{B}, w^{B}\right)$ was closed, then each individual offer must obey the constraints $F_{i} \geq F^{B}$ and $w_{i} \geq w^{B}$.

3. Each agent chooses whether to accept the offer made by "his" principal. If an agent rejects his principal's offer, he earns his outside option $u \geq 0$, and the respective principal produces nothing.

\footnotetext{
${ }^{11}$ This is equivalent to a horizontal move in figure 1 from $\left(w_{i}^{C}, w_{j}^{C}\right)$ to $\left(w_{i}^{D}, w_{j}^{C}\right)$.

${ }^{12}$ For the main results of our paper, the solution concept applied to the bargaining stage is immaterial, as long as the axioms of Pareto-optimality and individual rationality are satisfied.
} 
4. If $A_{i}$ has accepted the contract, he chooses his effort $e_{i}$. $Y_{i}\left(e_{i}\right)$ is produced, the market price for the good is determined, the produced amounts of the good are sold, and payoffs are paid to all the agents and the principals.

We have already demonstrated in section 3.3 that a stable cartel agreement would maximize the joint payoff. Hence, the Nash bargaining result concerning the piece rate is already derived, as $w^{B}=w_{i}^{C}$ is a necessary condition to satisfy the axiom of Pareto-superiority. ${ }^{13}$

If the collective wage agreement stabilizes the product market cartel, then it generates an agreement rent for the four players. This rent is distributed between the negotiating parties via a fixed wage that may exceed the minimum fixed wage in the cartel situation: $F^{B} \geq F_{i}^{C}$. Then, $\left(F^{B}-F_{i}^{C}\right) \geq 0$ is the additional fixed wage each firm pays under the collective wage agreement. The union's share of the agreement rent, therefore, amounts to $2\left(F^{B}-F_{i}^{C}\right)$.

The employers association's share of the agreement rent is computed as follows: each firm receives the cartel profit minus its contribution to the union, and gives up the disagreement payoff, namely the duopoly profit. Hence, the employers' share amounts to $2\left[\Pi_{i}^{C}-\left(F^{B}-F_{i}^{C}\right)-\Pi_{i}^{D}\right]$. This allows us to state the Nash product as

$$
4\left[\Pi_{i}^{C}-\left(F^{B}-F_{i}^{C}\right)-\Pi_{i}^{D}\right]\left[F^{B}-F_{i}^{C}\right] .
$$

The symmetric Nash bargaining solution $\hat{F}^{B}$ maximizes this Nash product. The first-order condition for an interior solution is $\Pi_{i}^{C}-\Pi_{i}^{D}-2\left(F^{B}-F_{i}^{C}\right) \stackrel{!}{=} 0$, which yields

$$
\hat{F}^{B}=\frac{\Pi_{i}^{C}-\Pi_{i}^{D}}{2}+F_{i}^{C}
$$

Each firm pays a part of the additional profit to its employee, in excess of the minimum fixed wage in the cartel solution. ${ }^{14}$ The individual profit of each firm is smaller than in a cartel without the collective wage agreement $\left(\Pi_{i}^{B}<\Pi_{i}^{C}\right)$, but exceeds the individual duopoly profit: $\Pi_{i}^{B}>\Pi_{i}^{D}$.

Figure 3 visualizes the situation within one firm under a collective wage agreement $\left(F^{B}, w^{B}\right)$, represented by point $\mathrm{B}$. As the collective wage agreement consists of a higher fixed wage, the derivation area is shifted upwards, compared to the cartel solution. The lower profit level corresponds with a higher isoprofit curve (for $w_{j}=a / 3$ ). Since the agent's participation constraint remains unmodified, the size of the lens increases. Nevertheless, as figure 3 shows, the only intersection between lens and the permitted deviations area is the point B itself. Thus, the collective wage agreement prohibits any deviation form it that is bilaterally beneficial.

\footnotetext{
${ }^{13}$ Hence, effort costs can be excluded from the derivation of the Nash product. Note that this simplification is only possible in models with linear demand and quadratic effort costs. In other models, the efficient variable wage is not necessarily constant, as it has been pointed out in the literature on monopoly unions and efficient bargaining, see, e.g., McDonald/Solow (1981) or Espinosa/Rhee (1989).

${ }^{14}$ Substitution of the results derived above (see table 1 ) yields $\hat{F}^{B}=u-47 a^{2} / 1800$ as the expressive solution.
} 
Figure 3: Intra-firm incentives with collective wage agreement

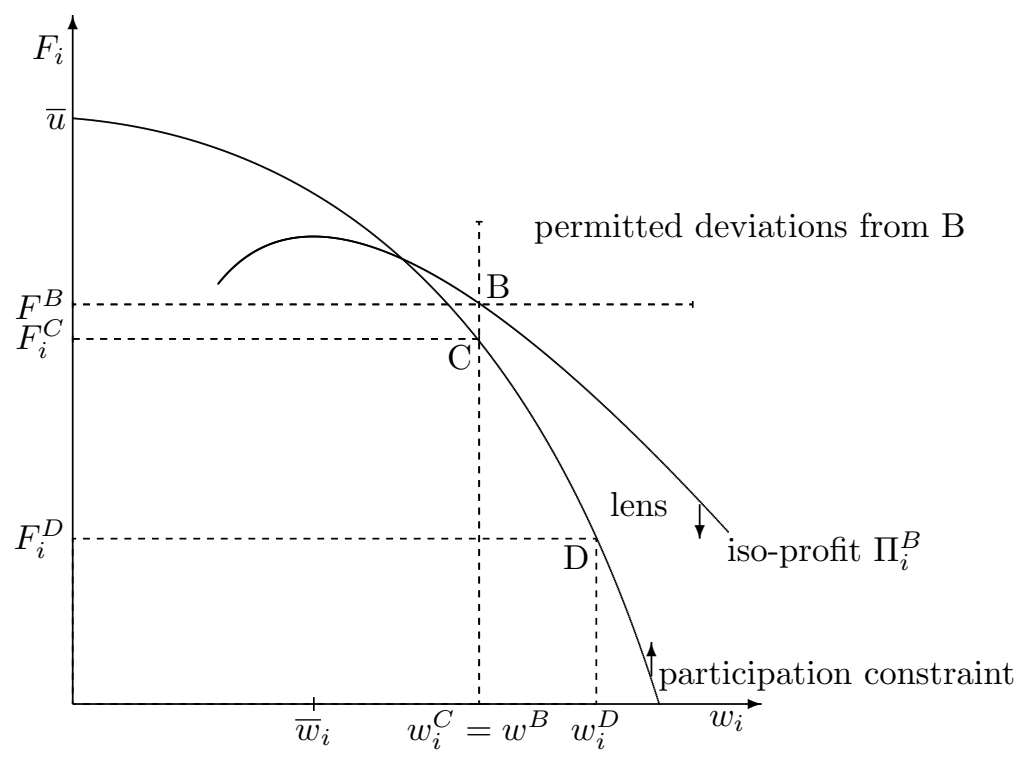

\section{Conclusion}

We have set up a model that combines a Cournot duopoly with intra-firm conflicts in the context of a simple moral hazard model, and we have derived the Cournot equilibrium in wages. We also have derived the wages an enforceable cartel (with two production sites and convex marginal costs) would choose. The cartel would choose lower variable wages, in order to reduce output, and pay a higher fixed wage.

The cartel wage structure, however, does not constitute a subgame perfect equilibrium. Insofar, the wage cartel does not differ from the production quota cartel. But there is one important difference between these two settings: while the quota cartel is illegal, a collective wage agreement can legally be enforced. This endows the labor union with a position which is remarkably similar to the economic function of the Sicilian mafia, as described by Bandiera (2003). ${ }^{15}$ The distribution of the cartel rent between the two firms and a labor union according to the Nash bargaining solution requires a side payment to the benefit of the union (or its members). This side payment may take the form of a higher fixed wage. ${ }^{16}$

\footnotetext{
${ }^{15}$ According to this paper, the mafia provided enforcement for cartels in order to extract a share of the increased profits. See also McNollgast (1999); these authors describe how regulation may establish or stabilize cartels.

${ }^{16}$ Thus, our results are in contrast to those of Chemla (2003), who finds that upstream monopolists may capture a higher share of the decreasing rents of the downstream market as competition becomes more intensive. In our model, the upstream union may bargain for a
} 
The principal-agent model we have employed here is rather simple, yet sufficient to derive the basic insights. The limitation of our focus to linear contracts is a prerequisite for the stabilizing effect of enforceable collective wage agreements. However, more sophisticated model of intra-firm conflicts may lead to similar results. There are many options to enrich the model. E.g., we could introduce risk-aversion on the side of the agent, but this would only reinforce the derived results.

The insights of this paper are relevant for strategic management considerations. They also may contribute a solution to the "fixed wage puzzle": while economic theory strongly favors variable payment, fixed wages are omnipresent in the real world. According to our results, firms in an oligopoly situation have an incentive to pay higher fixed and lower variable wages than isolated firms. Such an incentive structure would appear inefficient when the analysis neglects the strategic competition on the product market.

Moreover, the results of this paper are relevant for economic policy, and in particular for regulation of competition. Cartel authorities should not only look at direct cartel agreements when trying to identify illegal collusive behavior. Collective wage agreements may also be suspicious, in particular if they provide intra-firm incentives that appear inefficient at the first glance.

\section{References}

Aggarwal, Rajesh K. / Samwick, Andrew A. 1999: Executive Compensation, Strategic Competition, and Relative Performance Evaluation: Theory and Evidence. In: The Journal of Finance 54(6), 1999-2043.

Alexander, Cindy R./Reifen, David Vertical Contracts as Strategic Commitments: How Are They Enforced? in: Journal of Economics and Management Strategy 4(4), 623-649.

Amable, Bruno / Gatti, Donatella 2001: Product Market Competition and Employment Protection: a Case for Policy Complementarity; unpublished mimeo.

Amable, Bruno / Gatti, Donatella 2002: Macroeconomic Effects of Product Market Competition in a Dynamic Efficiency Wage Model. In: Economics Letters 75(1), 39-46.

Bandiera, Oriana 2003: Land Reform, the Market for Protection, and the Origins of the Sicilian Mafia: Theory and Evidence. In: The Journal of Law, Economics, and Organization 19(1), 218-244.

Berle, Adolf A. / Means, Gardiner C. 1932: The Modern Corporation and Private Property; Macmillan; New York.

lager share when the collective wage agreement helps to stabilize a cartel on the downstram market. 
Bensaïd, Bernard / Gary-Bobo, Robert J. 1991: Negotiation of ProfitSharing Contracts in Industry. In: European Economic Review 35(5), 1069-1085.

Bornstein, Gary/Gneezy, Uri 2002: Price Competition Between Teams. In: Experimental Economics 5, 29-38.

Chemla, G. 2003: Downstream Competition, Foreclosure, and Vertical Integration. In: Journal of Economics and Management Strategy 12(2), 261-289.

Espinosa, M. P./Rhee, C. 1989: Efficient Wage Bargaining as a Repeated Game. In: The Quarterly Journal of Economics 104, 565-588.

Fee, C. Edward / Hadlock, Charles J. 2000: Management Turnover and Product Market Competition: Empirical Evidence from the U.S. Newspaper Industry. In: Journal of Business 73(2), 205-243.

Fershtmann, Chaim / Judd, Kenneth L. 1987: Equilibrium Incentives in Oligopoly. In: The American Economic Review 77(5), 927-940.

Gal-Or, Esther 1995: Correlated Contracts in Oligopoly. In: International Economic Review 36(1), 75-100.

Gaver, Jennifer J. / Gaver, Kenneth M. / Battistel, George P. 1992: The Stock Market Reactions to Performance Plan Adaptions. In: The Accounting Review 67(1), 172-182.

Glazer, Jakob / Israel, Ronen 1990: Managerial Incentives and Financial Signaling in Product Market Competition. In: International Journal of Industrial Organization 8(2), 271-280.

Goering, Gregory E. / Harikumar, T. 1999: Investment Decisions and Managerial Compensation Design in the Presence of Product Market Rivalry. In: Managerial and Decision Economics 20, 87-97.

Gonzáles-Maestro, Miguel 2000: Divisionalization and Delegation in Oligopoly. In: Journal of Economics and Management Strategy 9(3), 321-338.

Hart, Oliver 1983: The Market Mechanism as an Incentive Scheme. In: The Bell Journal of Economics 14(3), 366-382.

Hart, R.A. 1990: Profit Sharing and Work Sharing. In: Economics Letters 34(1), 11-14.

Haucap, J./Pauly, U./Wey, C. 2001: Collective Wage Setting when Wages are Generally Binding: An Antitrust Perspective. In: International Review of Law and Economics 21(3), 287-307. 
Hermalin, Benjamin E. 1992: The Effects of Competition on Executive Behavior. In: RAND Journal of Economics 23(3), 350-365.

Holmstrom, B. 1982: Moral Hazard in Teams. In: Bell Journal of Economics 13(2), 324-340.

Katz, Harry C./MacDuffie, John P./Pil, Frits K. 2002: Collective Bargaining in the US Auto Industry; Working Paper, published in: Clark, Paul F./Delaney, John T./Frost, Ann C. (eds.): Collective Bargaining in the Private Sector. 2002 IRRA Research Volume; published by the Labor and Employment Relations Association, Champaign, IL.

Kühn, Kai-Uwe 1994: Labour Contracts, Product Market Oligopoly, and Involuntary Unemployment. In: Oxford Economic Papers 46(3), 366-384.

Leibenstein, Harvey 1966: Allocative Efficiency vs. 'X-Inefficiency'. In: The American Economic Review 56 (3), 392-415.

McDonald, I.M./Solow, R.M. 1981: Wage Bargaining and Employment. In: The American Economic Review 71(5), 896-908.

McNollgast 1999: (McCubbins, M.D./Noll, R.G./Weingast, B.R.) The Political Origins of the Administrative Procedure Act. In: The Journal of Law, Economics, and Organization 15(1), 180-217.

Nalebuff, Barry J. / Stiglitz, J. E. 1983: Information, Competition, and Markets. In: The American Economic Review 73(2), 278-283.

Nickel, Stephen J. 1996: Competition and Corporate Performance. In: Journal of Political Economy 104(4), 724-746.

Nygaard, Arne / Myrtveit, Ingunn 2000: Moral Hazard, Competition and Contract Design: Empirical Evidence from Managerial, Franchised and Entrepreneurial Businesses in Norway. In: Applied Economics 32, 349-356.

Reitman, David 1993: Stock Options and the Strategic Use of Managerial Incentives. In: The American Economic Review 83(3), 513-524.

Richards, Daniel J. 1983: Wages and the Dominant Firm. In: Journal of Labor Research 4 (2), 177-182.

Saracho, Ana I. 2002: Patent Licensing Under Strategic Delegation. In: Journal of Economics and Management Strategy 11(2), 225-251.

Schmidt, K. 1997: Managerial Incentives and Product Market Competition. In: Review of Economic Studies 64, 191-214.

Sklivas, Steven D. 1987: The Strategic Choice of Managerial Incentives. In: RAND Journal of Economics 18(3), 452-458. 
Stewart, Geoff 1989: Profit-Sharing in Cournot Oligopoly. In: Economics Letters 31, 221-224.

Tombak, Mihkel M. 2002: Mergers to Monopoly. In: Journal of Economics and Management Strategy 11(3), 513-546.

Toulemonde, Eric 1999: Deterring through High Wages. University of Aarhus, Working Paper 1999-17.

Weitzman, Martin L. 1985: The Simple Macroeconomics of Profit-Sharing. In: The American Economic Review 75(5), 937-953. 